\title{
Revisiting the role of neurons in neurovascular coupling
}

\author{
Bruno Cauli' and Edith Hamel ${ }^{2 *}$ \\ ' Laboratoire de Neurobiologie des Processus Adaptatifs, Université Pierre et Marie Curie, Paris, France \\ 2 Laboratory of Cerebrovascular Research, Montreal Neurological Institute, Montréal, QC, Canada
}

\author{
Edited by: \\ Anna Devor, University of California \\ San Diego, USA \\ Reviewed by: \\ Karl A. Kasischke, University of \\ Rochester Medical Center, USA; \\ Rochester University, USA \\ Bruno Weber, University of Zurich, \\ Switzerland \\ *Correspondence: \\ Edith Hamel, Laboratory of \\ Cerebrovascular Research, Montreal \\ Neurological Institute, 3801 University \\ Street, Montréal, OC H3A 2B4, \\ Canada. \\ e-mail:edith.hamel@mcgill.ca
}

In this article, we will review molecular, anatomical, physiological and pharmacological data in an attempt to better understand how excitatory and inhibitory neurons recruited by distinct afferent inputs to the cerebral cortex contribute to the coupled hemodynamic response, and how astrocytes can act as intermediaries to these neuronal populations. We aim at providing the pros and cons to the following statements that, depending on the nature of the afferent input to the neocortex, (i) different neuronal or astroglial messengers, likely acting in sequence, mediate the hemodynamic changes, (ii) some recruited neurons release messengers that directly alter blood vessel tone, (iii) others act by modulating neuronal and astroglial activity, and (iv) astrocytes act as intermediaries for both excitatory and inhibitory neurotransmitters. We will stress that a given afferent signal activates a precise neuronal circuitry that determines the mediators of the hemodynamic response as well as the level of interaction with surrounding astrocytes.

Keywords: neuronal network, inhibitory interneuron, excitatory pathways, astrocytes, cerebral blood flow

\section{ACTIVITY IN NEURONAL NETWORKS UNDERLIES ACTIVITY- DEPENDENT CHANGES IN HEMODYNAMIC SIGNALS}

The temporal and spatial coupling between increased neuronal activity and cerebral blood flow (CBF), known as functional hyperemia or neurovascular coupling, is a highly regulated phenomenon that ensures adequate supply of oxygen and glucose to the neurons at work during a given task. Although intuitively appealing, a direct link between energy state and blood flow is not universally accepted, and the physiological basis of neurovascular coupling still remains uncertain. Indeed, neither the lack of glucose or oxygen appears to fully justify the hemodynamic response (Powers et al., 1996; Wolf et al., 1997; Lindauer et al., 2010), which may serve as a safety measure for substrate delivery during functional activation (Leithner et al., 2010). Despite these limitations, the changes in hemodynamic signals (BOLD response, $\mathrm{CBF}$ or cerebral blood volume, $\mathrm{CBV}$ ) are commonly used as surrogate markers to map changes in neural activity in brain imaging procedures, such as functional magnetic resonance (fMRI), positron emission tomography (PET), or diffuse optical imaging (DOI) under both physiological and pathological conditions. Accordingly, an adequate interpretation of imaging data imperatively requires understanding of the cellular basis of the activated neurocircuitry and its interaction with astrocytic and vascular targets. In contrast to the innervation of large cerebral arteries by ganglia from the peripheral nervous system, which is mainly involved in autoregulation (for a review, Hamel, 2006), the neuronal circuitry at play here refers to pathways of the central nervous system that interact with the brain microcirculation.

As such, it is known that the changes in activity are triggered by the incoming afferents, but that it is their local processing by the targeted cells that drives the perfusion changes (Logothetis et al., 2001; Lauritzen and Gold, 2003; Lauritzen, 2005). These hemodynamic changes are mainly, if not exclusively, achieved by the control of the vasculature at the arteriolar level (Hillman et al., 2007), from the pial surface down to the precapillary level where vascular pericytes stand (Jones, 1970), the latter contractile elements being likely involved in a localized control of capillary tone (Peppiatt et al., 2006). Additionally, it has been shown that the hemodynamic response correlates with synchronized synaptic activity, a highly energy consuming process (Arthurs et al., 2000), and that it is controlled by signaling molecules released during increased synaptic activity (Devor et al., 2007). Recently, using the neurovascular coupling response to various sensory stimuli (whisker, forepaw or hindpaw, visual), elegant experiments demonstrated that the spread of the hemodynamic activity accurately reflects the neural response (Berwick et al., 2008), that it is driven by synaptic activity generated by intracortical processing (Franceschini et al., 2008), and that the latter reflected the balance between excitatory and inhibitory signals (Devor et al., 2005, 2007; Shmuel et al., 2006). Particularly, suppressed neuronal activity or functional neuronal inhibition has been associated with decrease in blood oxygenation and perfusion, which could explain the negative BOLD signals (Shmuel et al., 2002, 2006) as it occurred concurrently with arteriolar constriction (Devor et al., 2007).

\section{IDENTIFICATION OF THE UNDERLYING NEURONAL CIRCUITRY}

As an attempt to identify the underlying neuronal circuitry, an interesting study by Lu et al. (2004) showed that laminar BOLD and $\mathrm{CBV}$ responses to rat whisker stimulation spatially correlated with increased neuronal activity evaluated by c-Fos upregulation. In an unrelated study in rats treated with the serotonin releasing drug m-chlorophenylpiperazine, positive BOLD signals and c-Fos immunoreactivity correlated in areas of increased activity, but not in those that displayed diminished BOLD signals, presumably due to decreased neuronal signaling (Stark et al., 2006). Recently, it was shown that stimulation of corticocortical and thalamocortical inputs to the same area of the somatosensory cortex induced completely distinct frequency-dependent changes in CBF and oxygen consumption, and evoked activity in different populations of 
cortical excitatory pyramidal cells and inhibitory GABA interneurons (Enager et al., 2009). Stimulation intensity increases occurred with the silencing or recruitment of distinct inhibitory interneurons, indicating that neural network activation is both stimulusand frequency-dependent. Particularly, the hemodynamic responses were attributed to activation of cyclooxygenase-2 (COX-2) pyramidal cells and somatostatin (SOM)/nitric oxide synthase (NOS) inhibitory interneurons, consistent with pharmacological studies that implicated COX-2- and NOS-derived vasodilator messengers in these neurovascular pathways (Niwa et al., 2000; Gotoh et al., 2001; Hoffmeyer et al., 2007). Moreover, increased activity in inhibitory interneurons has been associated with the initiation of the hemodynamic response triggered by synchronized cortical activity, as induced by activation of the basal forebrain (Niessing et al., 2005). Stimulation of this basalocortical afferent input further indicated selective activation of cholinoceptive layers II to VI SOM and neuropeptide Y (NPY) interneurons, as well as layer I GABA interneurons, with widespread activation of pyramidal cells, including those that contain COX-2 (Kocharyan et al., 2008; Lecrux et al., 2009). Although it was demonstrated that the CBF response was triggered by cholinergic afferents, its full expression required $\mathrm{GABA}_{\mathrm{A}}$-mediated transmission on neuronal, vascular and/or astrocytic targets (Kocharyan et al., 2008). Together these anatomical, neurochemical and functional studies demonstrate the importance of identifying the cellular ensemble that underlies hemodynamic signals, highlighting that specific subsets of neurons are activated by a given stimulus, depending on the afferent input they receive and integrate.

\section{PERIVASCULAR ASTROCYTES AS INTERMEDIARIES TO BOTH GLUTAMATE AND GABA PATHWAYS}

In addition to the difficulty in identifying the exact contribution of excitatory and inhibitory neurotransmissions in the evoked hemodynamic response, the effect of these neurotransmitter systems on perivascular astrocytes needs to be considered (for a detailed review, Carmignoto and Gomez-Gonzalo, 2009). The enwrapping of synapses and blood vessels (Kacem et al., 1998) by glial processes and, particularly, their intervening endfeet in multiple neurovascular appositions identified at the ultrastructural level led to the concept of a neuronal-astrocytic-vascular tripartite functional unit (Vaucher and Hamel, 1995; Cohen et al., 1996; Paspalas and Papadopoulos, 1996; Vaucher et al., 2000). The significance of these interactions in the regulation of CBF was first substantiated by the demonstration that astrocytes could synthesize vasodilatory messengers (Table 1), particularly epoxyeicosatrienoic acids (EETs) generated from P450 arachidonic acid epoxygenase activity (Alkayed et al., 1996) that were involved in the CBF response to glutamate (Alkayed et al., 1997; Harder et al., 1998). Soon after came the first in vitro (in cortical slices) and in vivo demonstrations for a role of astrocytes, through metabo-

Table 1 | Summary of neuronal and gial mediators of functional hyperemia.

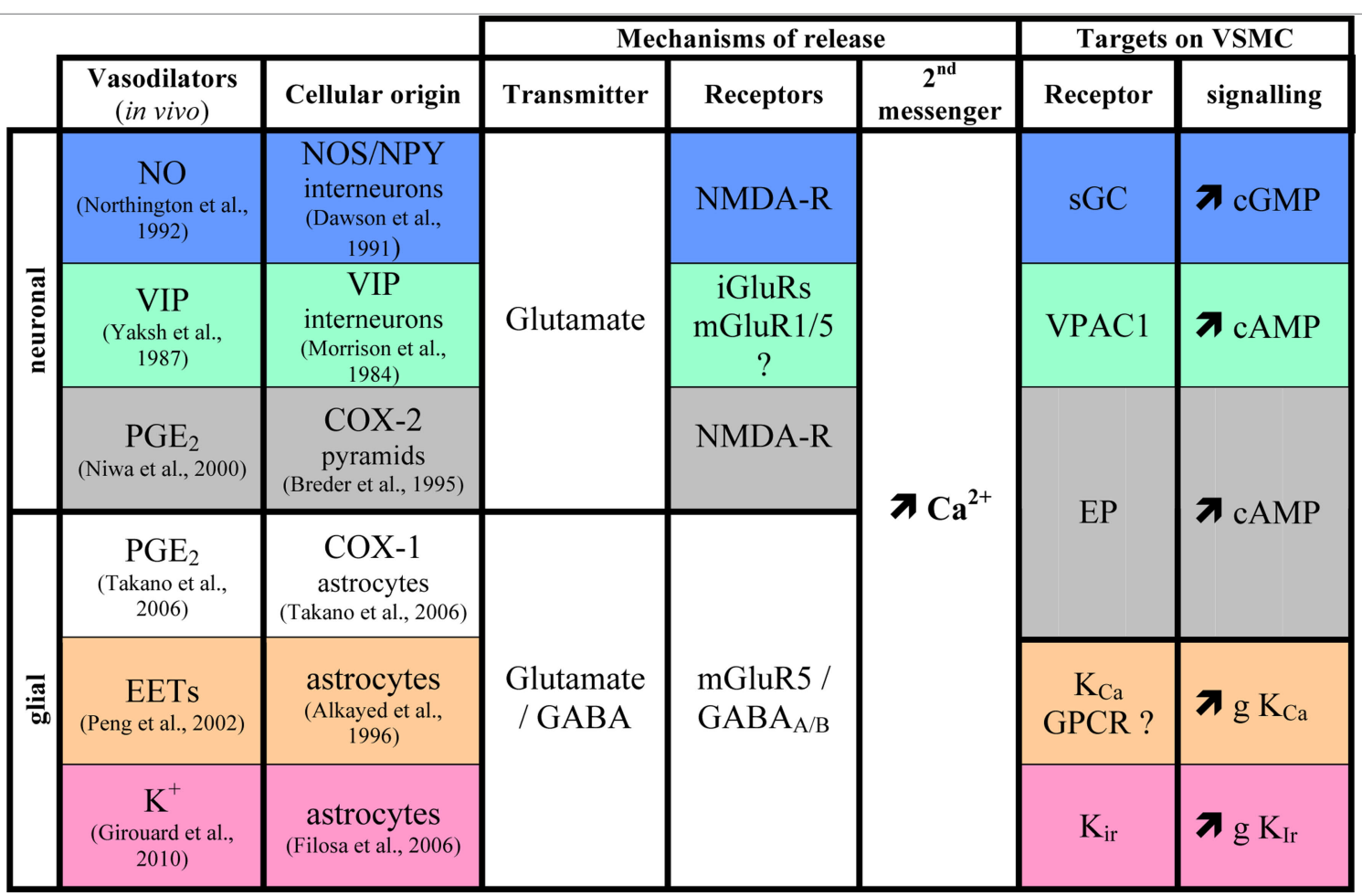

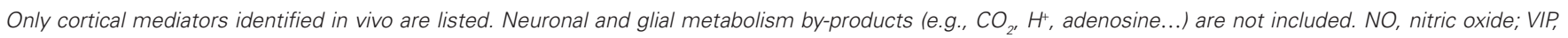
vasoactive intestinal polypeptide; PgE $2_{2}$ prostaglandin $E_{2} ; E E T s$, epoxyeicosatrienoic acids; NOS, nitric oxide synthase; NPY, neuropeptide Y; COX, cyclooxygenase, NMDA-R, N-methyl D aspartate receptors, iGluRs; ionotropic glutamate receptors, mGluR, metabotropic glutamate receptors; VSMC, vascular smooth muscle cell, SGC, soluble guanylate cyclase, VPAC1, VIP/PACAP receptor type 1; EP, prostaglandin $E_{2}$ receptors; GPCR, G protein coupled receptor. $K_{C a^{\prime}}$ Ca ${ }^{2+}$-activated $K^{+}$channels; $K_{i{ }^{\prime}}$ inward rectifier $K^{+}$channels; $g$, conductance. References can be found in the main list. 
tropic glutamate receptor (mGluRs)-induced $\mathrm{Ca}^{2+}$ transients, in microarteriolar dilation and the increase blood flow to forepaw stimulation, a response mediated by arachidonic acid products, possibly prostaglandin $\mathrm{E}_{2}\left(\mathrm{PGE}_{2}\right)$ (Zonta et al., 2003). Since this pioneer study, a role for astrocytes in neurovascular coupling has been reaffirmed in various paradigms (Carmignoto and GomezGonzalo, 2009).

Another pathway activated in astrocytic endfeet following $\mathrm{Ca}^{2+}$ increases is the large-conductance, calcium-sensitive potassium (BK) channels that induce $\mathrm{K}^{+}$release (Table 1 ), activation of smooth muscle Kir channels and relaxation (Filosa et al., 2006). Recently, it was shown that the extent of the $\mathrm{Ca}^{2+}$ increases in astrocytic endfeet determined the dilatory or contractile nature of the vascular response, both mediated by extracellular $\mathrm{K}^{+}$ (Girouard et al., 2010). This novel mechanism would reunify previous "apparently" contradictory findings, in brain slices or in retina, of dilation and constriction being induced by increased $\mathrm{Ca}^{2+}$ signaling in astrocytes, and explained by the levels of NO (Mulligan and MacVicar, 2004; Metea and Newman, 2006), oxygen (Gordon et al., 2008), or the pre-existing tone of the vessels (Blanco et al., 2008). Further, the study by Girouard et al. (2010) showed that neuronal activation in vitro (electrical field stimulation) similarly acted through serial activation of astrocytic BK and smooth muscle Kir channels. Considering that GABA (Nilsson et al., 1993; Serrano et al., 2006; Meier et al., 2008) and peptides such as SOM that colocalize with GABA (Somogyi et al., 1984; Cauli et al., 2000) in interneurons also increase $\mathrm{Ca}^{2+}$ signaling in astrocytes, (Straub et al., 2006), the latter could act as intermediaries to GABA in neurovascular coupling (Table 1). Whether or not the astrocytic/smooth muscle BK and Kir channel activation cascade is involved still remains to be determined. Similarly, it would be interesting to evaluate if the latter, or other contractile mechanisms of neuronal (Cauli et al., 2004; Rancillac et al., 2006) or vascular origins (Mulligan and MacVicar, 2004) could explain the dilatory and constrictive phases seen in the central core of neuronal depolarization and surround region of hyperpolarization, respectively, after somatosensory stimulation (Devor et al., 2007). To date the cellular and molecular mechanisms or even the functional significance of this response remains unknown.

\section{NEURALLY-DERIVED VASOACTIVE MESSENGERS}

In addition to the astrocyte-derived vasodilatory messengers $\mathrm{PGE}_{2}$ (Zonta et al., 2003), EETs (Alkayed et al., 1996), or K ${ }^{+}$ions (Filosa et al., 2006), some vasodilators are chiefly synthesized by distinct neuronal populations (Table 1). These include COX-2-derived prostanoids (Niwa et al., 2000) produced by some Layer II-III pyramidal cells (Yamagata et al., 1993; Breder et al., 1995), nitric oxide (NO) (Gotoh et al., 2001) whose synthetic enzyme is expressed by discrete subpopulations of cortical GABA interneurones (Kubota et al., 1994), VIP (Yaksh et al., 1987), acetylcholine (Scremin et al., 1973) and corticotropin-releasing factor (De Michele et al., 2005) synthesized by bipolar/bitufted GABA interneurones (Morrison et al., 1984; Chédotal et al., 1994a; Cauli et al., 1997; Gallopin et al., 2006). As for astrocyte-derived messengers, their release is stimulated by glutamatergic neurotransmission (Wang et al., 1986; Faraci and Breese, 1993; Pepicelli et al., 2005). For instance the highly
$\mathrm{Ca}^{2+}$ permeable NMDA receptors, expressed by cortical neurons (Monyer et al., 1994; Cauli et al., 2000), promote the release of $\mathrm{PGE}_{2}$ (Pepicelli et al., 2005) and NO (Faraci and Breese, 1993).

Alike astrocytes, some GABA interneurons produce substances with vasocontractile properties, namely NPY (Abounader et al., 1995; Cauli et al., 2004) and SOM (Long et al., 1992; Cauli et al., 2004). Cortical neurons producing these vasoactive peptides are intimately associated with blood vessels through neuronal-astrocytic-vascular appositions described above (Chédotal et al., 1994b; Abounader and Hamel, 1997; Estrada and DeFelipe, 1998; Vaucher et al., 2000; Wang et al., 2005), and their receptors are expressed by smooth muscle cells and astrocytes (Chalmers et al., 1995; Bao et al., 1997; Abounader et al., 1999; Fahrenkrug et al., 2000; Cauli et al., 2004; Straub et al., 2006; Cahoy et al., 2008). This raises the intriguing question of whether or not astrocytes are intermediaries for neuron-derived vasoactive messengers or, alternatively, if the latter exert direct effects on the microcirculation.

\section{TEMPORAL SEOUENCES IN THE RECRUITMENT OF NEURONS AND ASTROCYTES}

It is widely admitted that an increase in intracellular $\mathrm{Ca}^{2+}($ Table $\mathbf{1})$ is a required early event for the production and/or release of vasoactive messengers from neurons (Lauritzen, 2005) and astrocytes (Straub and Nelson, 2007). Examination of $\mathrm{Ca}^{2+}$ dynamics in these cell types could provide a clue to decipher their relative and temporal contribution to functional hyperemia. The general view is that rapid $\mathrm{Ca}^{2+}$ events reflect an entry following fast (10-12 ms) spiking response of neurons (Petersen et al., 2003) and/or activation of $\mathrm{Ca}^{2+}$ permeable ionotropic receptors, whereas slower dynamics are mainly driven by activation of metabotropic receptors leading to the release of $\mathrm{Ca}^{2+}$ from intracellular stores (Perea and Araque, 2005). Hence, cortical neurons, which express more frequently and abundantly ionotropic glutamate receptors (Monyer et al., 1994; Cauli et al., 2000) than astrocytes (Conti et al., 1997; Cahoy et al., 2008), are likely to be responsible for the majority of fast $\mathrm{Ca}^{2+}$ responses. In contrast, group I mGluRs ubiquitously expressed by cortical neurons (Baude et al., 1993; Cauli et al., 2000) and astrocytes (Porter and McCarthy, 1996) would be responsible for slower $\mathrm{Ca}^{2+}$ dynamics in both cell types. Consistent with this, in somatosensory or visual cortex, evoked $\mathrm{Ca}^{2+}$ events in neurons are virtually locked with sensory stimulations and precede those in astrocytes by a few seconds (Stosiek et al., 2003; Ohki et al., 2005; Wang et al., 2006; Schummers et al., 2008; Murayama et al., 2009), although a small proportion $(-5 \%)$ of astrocytes can exhibit $\mathrm{Ca}^{2+}$ responses as fast as neurons (Winship et al., 2007).

Calcium uncaging in astrocytic endfeet in vivo showed that arterioles start to dilate $\sim 500 \mathrm{~ms}$ after the onset of $\mathrm{Ca}^{2+}$ increase (Takano et al., 2006) indicating that synthesis, release and effects of vasodilatory messengers must be achieved within this time window. Since hemodynamic responses initiate $\sim 600 \mathrm{~ms}$ after the onset of sensory stimulations (Kleinfeld et al., 1998; Devor et al., 2003), it appears that only cell types exhibiting fast evoked $\mathrm{Ca}^{2+}$ events (i.e., less than $100 \mathrm{~ms}$ ) can account for the early phase of the hemodynamic response. Therefore, vasoactive messengers produced by neurons and, possibly, also by astrocytes with fast $\mathrm{Ca}^{2+}$ events, could explain this response (Figure 1). 

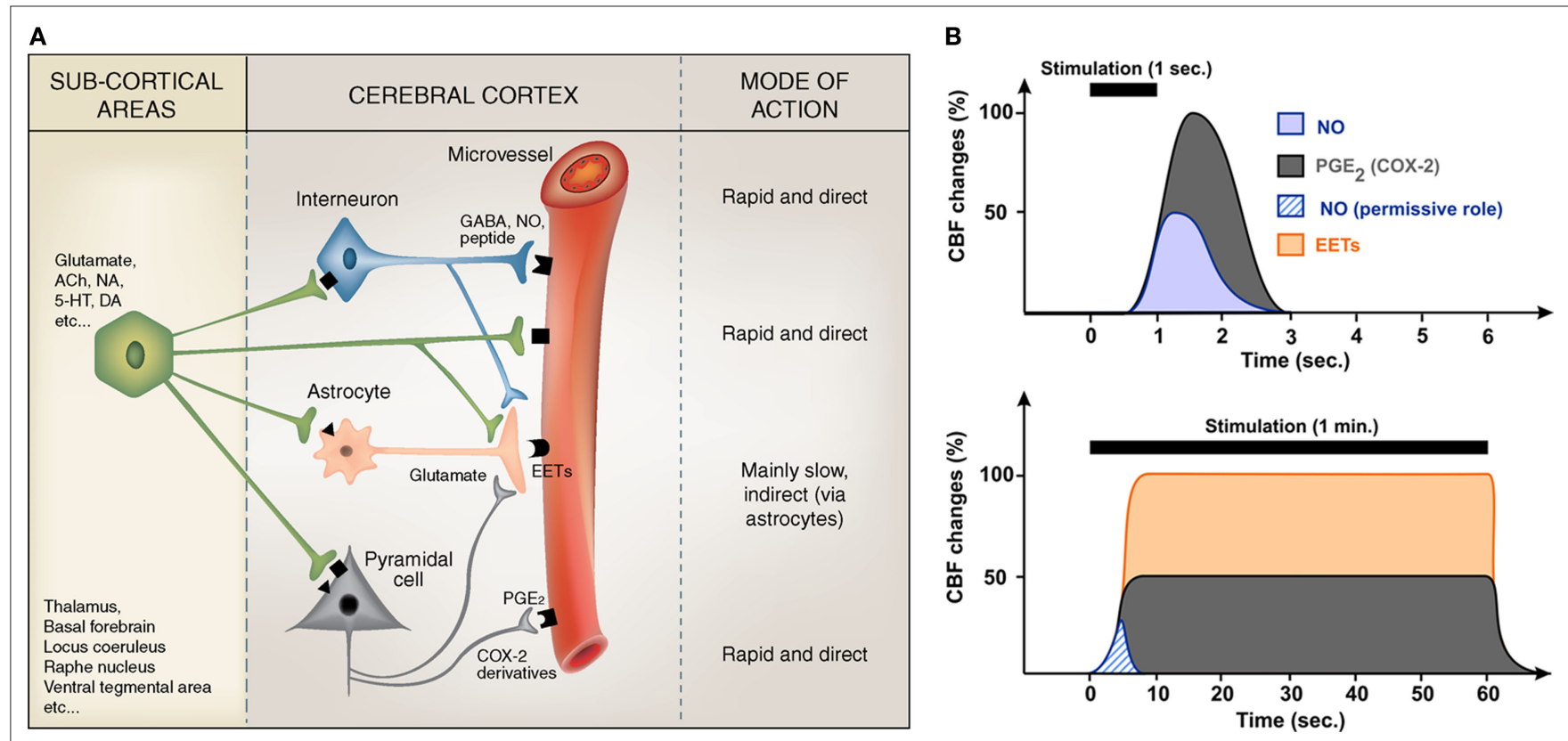

FIGURE 1 | Summary of the proposed regulation of cortical microvessels by pyramidal cells, GABA interneurons and astrocytes (A), and how their respective effects can temporally regulate CBF changes (B). (A) Subcortical afferents from a variety of brain areas target distinct populations of neurons in the cerebral cortex. These activated neuronal networks can either directly act on local microvessels, which are endowed with receptors (geometric forms on the vessel wall) for most neurotransmitters/neuromediators, or indirectly via astrocytes that act as intermediaries to both pyramidal cells and interneurons. Known direct vasoactive mediators released from pyramidal cells and interneurons correspond respectively to COX-2 derivatives like prostaglandin E2 (PGE2) and NO and, possibly, GABA, whereas astrocytes act chiefly by releasing dilatory EETs, an effect comparatively slow as opposed to that of NO and PGE2 (or other neurally released vasoactive molecules or peptides). The possibility that sub-cortical afferents directly contact and act upon cortical astrocytes or microvessels also has to be taken into consideration. Modified from Figure 3 in Hamel (2006). (B) Schematic representation of the relative and temporal contributions of selected vasoactive mediators produced by pyramidal cells (PGE2), interneurons (NO) and astrocytes (EETs), to the CBF response evoked by sensory stimulation (see Table $\mathbf{1}$ for a more complete list). Brief stimulations (1 s) are more likely to involve neurally-derived mediators whereas sustained stimulation (1 $\mathrm{min}$ ) are more susceptible to recruit astrocyte-derived messengers. $\mathrm{NO}$ being transiently released its contribution to CBF response during sustained stimulation is minor and could account for its permissive role.

\section{MULTIPLICITY OF VASOACTIVE MESSENGERS: ARE THEY ALL REQUIRED?}

In the cerebral cortex, none of the vasoactive messengers implicated in neurovascular coupling (Girouard and Iadecola, 2006), whether of neuronal or astroglial origin, can individually account for the hemodynamic response, as demonstrated by genetic invalidation (Ma et al., 1996; Niwa et al., 2000, 2001; Kitaura et al., 2007) or synthesis inhibition (Lindauer et al., 1999; Peng et al., 2002; Hoffmeyer et al., 2007; Leithner et al., 2010). When individually summed the inhibition of these messengers largely exceeds the expected value of $100 \%$ (Iadecola, 2004), which suggests that their kinetics of action, temporal and spatial recruitment must be carefully considered to elucidate their relative contributions. Alternatively, this may suggest that the activated pathways do not obligatorily operate independently from each other, and that, under certain circumstances, some may act like modulator rather than mediator of the perfusion responses, as documented for NO in the somatosensory cortex (Lindauer et al., 1999).

NO, one of the fastest diffusible (Wood and Garthwaite, 1994) vasodilator produced by a subset NPY-expressing interneurons (Dawson et al., 1991) is likely to represent an immediate early messenger of neurovascular coupling. Correspondingly, Shibuki's group showed that neuronal NO can account for up to $50 \%$ of the CBF response evoked by a brief ( $1 \mathrm{~s}$ ) sensory stimulation (Kitaura et al., 2007). In contrast, others only found a permissive role for NO when long ( $1 \mathrm{~min}$ ) stimulations were used (Lindauer et al., 1999; Liu et al., 2008). These differences likely reflect the fact that NO release is transient (Buerk et al., 2003) which can be explained by the NO scavenging effect of hemoglobin and/or by the adaptation of NO producing interneurons (Karagiannis et al., 2009). In contrast, vasodilatory prostanoids produced by COX-2, which is chiefly expressed by pyramidal cells (Yamagata et al., 1993; Breder et al., 1995), account for $\sim 50 \%$ of the CBF response evoked by both sustained (Niwa et al., 2000) and brief stimulations (Kitaura et al., 2007). Consistent with an involvement of neuron-derived messengers in the early phase of neurovascular coupling, blockade of prostanoids and NO synthesis almost completely abolished hemodynamic responses evoked by brief sensory stimulations (Kitaura et al., 2007). During long lasting sensory stimulation, blockade of EETs synthesis (Peng et al., 2002) or their receptors (Liu et al., 2008) blocked about $50 \%$ of the blood flow response, demonstrating that EETs produced by astrocytes (Alkayed et al., 1996) are released during sustained neuronal activity.

Similarly, the local release of $\mathrm{K}^{+}$from astrocytic endfeet (Filosa et al., 2006) accounts for up to 50\% of the CBF increase evoked by long lasting sensory stimulations (Girouard et al., 2010; Leithner et al., 2010) Surprisingly, combined blockade of NOS, COXs, p450 epoxygenase, BK channels and adenosine receptors (Leithner 
et al., 2010) did not reach a total inhibition of the late phase of the hemodynamic response as expected from individual blockades (see above). This suggests that either multiple inhibition was incomplete or that other long lasting vasodilatory messengers are involved (Cauli et al., 2004), possibly VIP, which is contained within GABA interneurons targeted by thalamocortical afferents (Staiger et al., 1996) and released during sensory stimulation (Wang et al., 1985). Similarly vasodilatory messengers derived from the endothelium (Rosenblum, 1986) such as NO, prostacyclin (Faraci and Heistad, 1998) but also EETs (Campbell and Fleming, 2010), might be recruited under certain circumstances as it was reported for endothelial $\mathrm{NO}$ after muscarinic $\mathrm{m} 5$ receptor activation (Elhusseiny and Hamel, 2000; Yamada et al., 2001).

\section{CURRENT UNDERSTANDING, FUTURE DIRECTIONS AND CLINICAL IMPLICATIONS}

Current evidence suggests that neuronal and astroglial signals that transduce changes in neuronal activity into an integrated vascular response are highly dependent upon the neurotransmitter released by the incoming afferents, and strictly determined by the target neurons within the activated area. Particularly, depending on the nature of the afferent input ( $i$ ) different neuronal or astroglial messengers, likely acting in sequence, mediate the hemodynamic changes, (ii) some recruited neurons release messengers that can directly alter blood vessel tone, (iii) others act by modulating neuronal and astroglial activity, and (iv) astrocytes may act as intermediaries for both excitatory and inhibitory neurotransmitters (Figure 1).

Probably due to the large diversity of cortical neurons (Ascoli et al., 2008), to our knowledge, no in vivo study has yet investigated $\mathrm{Ca}^{2+}$ dynamics in identified neurons producing vasoactive substances or the vascular effects of their stimulation. The growing development of transgenic mice expressing genetically encoded fluorescent reporters and/or optogenetic tools (Cardin et al., 2009; Sohal et al., 2009) in discrete subsets of cortical neurons (Heintz, 2001) together with the emergence of ultrafast multispectral imag-

\section{REFERENCES}

Abounader, R., Elhusseiny, A., Cohen, Z., Olivier, A., Stanimirovic, D., Quirion, R., and Hamel, E. (1999). Expression of neuropeptide Y receptors mRNA and protein in human brain vessels and cerebromicrovascular cells in culture. J. Cereb. Blood Flow Metab. 19, 155-163.

Abounader, R., and Hamel, E. (1997). Associations between neuropeptide $\mathrm{Y}$ nerve terminals and intraparenchymal microvessels in rat and human cerebral cortex. J. Comp. Neurol. 388, 444-453.

Abounader, R., Villemure, J. G., and Hamel, E. (1995). Characterization of neuropeptide Y (NPY) receptors in human cerebral arteries with selective agonists and the new Y1 antagonist BIBP 3226. Br. J. Pharmacol. 116, 2245-2250.

Alkayed, N. J., Birks, E. K., Narayanan, J., Petrie, K. A., Kohler-Cabot, A. E.,

ing systems (Bouchard et al., 2009) that allow simultaneous monitoring of $\mathrm{Ca}^{2+}$ events and hemodynamics should help evaluate the contribution of specific neuronal types in neurovascular coupling. This should provide decisive conclusions on the temporal, spatial and extent of the neurally-driven hemodynamic alterations and how the latter can be interpreted in the context of brain imaging of normal or pathological physiology.

Indeed, since astrocytes appear as intermediary effectors in conveying signals for sustained hemodynamic responses, their alteration - primarily expressed by a state of chronic activation - in several chronic diseases of the central nervous system such as Alzheimer's disease or epilepsy, has to be seriously considered. Altered perfusion signals detected by fMRI, PET or DOI may represent astroglial dysfunction and not necessary impaired neuronal activity. Extending such thinking to the microcirculation itself, the functional endpoint in the intricate cascade of neuronal-astrocytic-vascular events evoked by increased brain activity, any diseases of the blood vessels themselves or alterations in their physical capacity to dilate or constrict, as seen in pathologies such as hypertension, diabetes, hypercholesterolemia and, even Alzheimer's disease (Iadecola, 2004; Zlokovic, 2008) would hinder the correct vascular response to totally normal neuronal activities. This further highlights that extreme caution should be applied to perfusion signals when making direct inference to altered neural activity (Schleim and Roiser, 2009; Ekstrom, 2010). Hence, a careful understanding of the neuronal circuitry at work will need to be interpreted in the context of a healthy or sick brain taking neuroinflammation and vascular diseases as possible confound factors.

\section{ACKNOWLEDGMENTS}

Bruno Cauli was supported by grants from the Human Frontier Science Program (HFSP) and the Centre National de la Recherche Scientifique (CNRS), and Edith Hamel from the Canadian Institutes of Health Research (CIHR).

D., Gardner, E. P., Goldberg, J. H., Helmstaedter, M., Hestrin, S., Karube, F., Kisvárday, Z. F., Lambolez, B., Lewis, D. A., Marin, O., Markram, H., Muñoz, A., Packer,A., Petersen, C. C., Rockland, K. S., Rossier, J., Rudy, B., Somogyi, P., Staiger,J.F., Tamas, G., Thomson,A.M., Toledo-Rodriguez, M., Wang, Y., West, D. C., and Yuste, R. (2008). Petilla terminology: nomenclature of features of GABAergic interneurons of the cerebral cortex. Nat. Rev. Neurosci. 9, 557-568.

Bao, L., Kopp, J., Zhang, X., Xu, Z. Q., Zhang, L. F., Wong, H., Walsh, J., and Hokfelt, T. (1997). Localization of neuropeptide Y Y1 receptors in cerebral blood vessels. Proc. Natl. Acad. Sci. U.S.A. 94, 12661-12666.

Baude, A., Nusser, Z., Roberts, J. D., Mulvihill, E., McIlhinney, R. A., and Somogyi, P. (1993). The metabotropic glutamate receptor (mGluR1 alpha) is concentrated at perisynaptic membrane of neuronal subpopulations as detected by immunogold reaction. Neuron 11, 771-787.

Berwick, J., Johnston, D., Jones, M., Martindale, J., Martin, C., Kennerley, A. J., Redgrave, P., and Mayhew, J. E. (2008). Fine detail of neurovascular coupling revealed by spatiotemporal analysis of the hemodynamic response to single whisker stimulation in rat barrel cortex. J. Neurophysiol. 99, 787-798.

Blanco, V. M., Stern, J. E., and Filosa, J. A. (2008). Tone-dependent vascular responses to astrocyte-derived signals. Am. J. Physiol. Heart Circ. Physiol. 294, H2855-H2863.

Bouchard, M. B., Chen, B. R., Burgess, S. A., and Hillman, E. M. (2009). Ultrafast multispectral optical imaging of cortical oxygenation, blood flow, and intracellular calcium dynamics. Opt. Express 17, 15670-15678.

Breder, C. D., Dewitt, D., and Kraig, R. P. (1995). Characterization of inducible 
cyclooxygenase in rat brain. J. Comp. Neurol. 355, 296-315.

Buerk, D. G., Ances, B. M., Greenberg, J. H., and Detre, J. A. (2003). Temporal dynamics of brain tissue nitric oxide during functional forepaw stimulation in rats. Neuroimage 18, 1-9.

Cahoy, J.D., Emery, B., Kaushal, A., Foo, L. C., Zamanian, J. L., Christopherson, K. S., Xing, Y., Lubischer, J. L., Krieg, P. A., Krupenko, S.A., Thompson, W. J., and Barres, B. A. (2008). A transcriptome database for astrocytes, neurons, and oligodendrocytes: a new resource for understanding brain development and function. J. Neurosci. 28, 264-278.

Campbell, W. B., and Fleming, I. (2010). Epoxyeicosatrienoic acids and endothelium-dependent responses. Pflugers Arch. 459, 881-895.

Cardin, J. A., Carlen, M., Meletis, K., Knoblich, U., Zhang, F., Deisseroth, K., Tsai, L. H., and Moore, C. I. (2009). Driving fast-spiking cells induces gamma rhythm and controls sensory responses. Nature 459, 663-667.

Carmignoto, G., and Gomez-Gonzalo, M. (2009). The contribution of astrocyte signalling to neurovascular coupling. Brain Res. Rev. 63, 138-148.

Cauli, B., Audinat, E., Lambolez, B., Angulo, M. C., Ropert, N., Tsuzuki, K., Hestrin, S., and Rossier, J. (1997). Molecular and physiological diversity of cortical nonpyramidal cells. J. Neurosci. 17, 3894-3906.

Cauli, B., Porter, J. T., Tsuzuki, K., Lambolez, B., Rossier, J., Quenet, B., and Audinat, E. (2000). Classification of fusiform neocortical interneurons based on unsupervised clustering. Proc. Natl. Acad. Sci. U.S.A. 97, 6144-6149.

Cauli, B., Tong, X. K., Rancillac, A., Serluca, N., Lambolez, B., Rossier, J., and Hamel, E. (2004). Cortical GABA interneurons in neurovascular coupling: relays for subcortical vasoactive pathways. J. Neurosci. 24, 8940-8949.

Chalmers, D. T., Lovenberg, T. W., and De Souza, E. B. (1995). Localization of novel corticotropin-releasing factor receptor (CRF2) mRNA expression to specific subcortical nuclei in rat brain: comparison with CRF1 receptor mRNA expression. J. Neurosci. 15, 6340-6350.

Chédotal, A., Cozzari, C., Faure, M. P., Hartman, B. K., and Hamel, E. (1994a). Distinct choline acetyltransferase (ChAT) and vasoactive intestinal polypeptide (VIP) bipolar neurons project to local blood vessels in the rat cerebral cortex. Brain Res. 646, 181-193.

Chédotal, A., Umbriaco, D., Descarries, L., Hartman, B. K., and Hamel, E. (1994b). Light and electron micro- scopic immunocytochemical analysis of the neurovascular relationships of choline acetyltransferase and vasoactive intestinal polypeptide nerve terminals in the rat cerebral cortex. J. Comp. Neurol. 343, 57-71.

Cohen, Z., Bonvento, G., Lacombe, P., and Hamel, E. (1996). Serotonin in the regulation of brain microcirculation. Prog. Neurobiol. 50, 335-362.

Conti, F., Minelli, A., DeBiasi, S., and Melone, M. (1997). Neuronal and glial localization of NMDA receptors in the cerebral cortex. Mol. Neurobiol. 14, 1-18.

Dawson, T. M., Bredt, D. S., Fotuhi, M., Hwang, P. M., and Snyder, S. H. (1991). Nitric oxide synthase and neuronal NADPH diaphorase are identical in brain and peripheral tissues. Proc. Natl. Acad. Sci. U.S.A. 88, 7797-7801.

De Michele, M., Touzani, O., Foster, A. C., Fieschi, C., Sette, G., and McCulloch, J. (2005). Corticotropin-releasing factor: effect on cerebral blood flow in physiologic and ischaemic conditions. Exp. Brain Res. 165, 375-382.

Devor,A., Dunn, A. K., Andermann, M. L., Ulbert, I., Boas, D. A., and Dale, A. M. (2003). Coupling of total hemoglobin concentration, oxygenation, and neural activity in rat somatosensory cortex. Neuron 39, 353-359.

Devor, A., Tian, P., Nishimura, N., Teng, I. C., Hillman, E. M., Narayanan, S. N., Ulbert, I., Boas, D. A., Kleinfeld, D., and Dale, A. M. (2007). Suppressed neuronal activity and concurrent arteriolar vasoconstriction may explain negative blood oxygenation level-dependent signal. J. Neurosci. 27, 4452-4459.

Devor, A., Ulbert, I., Dunn, A. K., Narayanan, S. N., Jones, S. R., Andermann, M. L., Boas, D. A., and Dale, A. M. (2005). Coupling of the cortical hemodynamic response to cortical and thalamic neuronal activity. Proc. Natl. Acad. Sci. U.S.A. 102, 3822-3827.

Ekstrom, A. (2010). How and when the fMRI BOLD signal relates to underlying neural activity: the danger in dissociation. Brain Res. Rev. 62, 233-244.

Elhusseiny, A., and Hamel, E. (2000). Muscarinic-but not nicotinic-acetylcholine receptors mediate a nitric oxide-dependent dilation in brain cortical arterioles: a possible role for the M5 receptor subtype. J. Cereb. Blood Flow Metab. 20, 298-305.

Enager, P., Piilgaard, H., Offenhauser, N., Kocharyan, A., Fernandes, P., Hamel, E., and Lauritzen, M. (2009). Pathway-specific variations in neurovascular and neurometabolic coupling in rat primary somatosensory cortex. J. Cereb. Blood Flow Metab. 29, 976-986.
Estrada, C., and DeFelipe, J. (1998). Nitric oxide-producing neurons in the neocortex: morphological and functional relationship with intraparenchymal microvasculature. Cereb. Cortex 8 193-203.

Fahrenkrug, J., Hannibal, J., Tams, J., and Georg, B. (2000). Immunohistochemical localization of the VIP1 receptor (VPAC1R) in rat cerebral blood vessels: relation to PACAP and VIP containing nerves. J. Cereb. Blood Flow Metab. 20, 1205-1214.

Faraci, F. M., and Breese, K. R. (1993). Nitric oxide mediates vasodilatation in response to activation of $\mathrm{N}$-methylD-aspartate receptors in brain. Circ. Res. 72, 476-480.

Faraci, F. M., and Heistad, D. D. (1998) Regulation of the cerebral circulation: role of endothelium and potassium channels. Physiol. Rev. 78, 53-97.

Filosa, J. A., Bonev, A. D., Straub, S. V., Meredith, A. L., Wilkerson, M. K., Aldrich, R. W., and Nelson, M. T. (2006). Local potassium signaling couples neuronal activity to vasodilation in the brain. Nat. Neurosci. 9, 1397-1403.

Franceschini, M. A., Nissila, I., Wu, W. Diamond, S. G., Bonmassar, G., and Boas, D. A. (2008). Coupling between somatosensory evoked potentials and hemodynamic response in the rat Neuroimage 41, 189-203.

Gallopin, T., Geoffroy, H., Rossier, J., and Lambolez, B. (2006). Cortical sources of CRF, NKB, and CCK and their effects on pyramidal cells in the neocortex. Cereb. Cortex 16, 1440-1452.

Girouard, H., Bonev, A. D., Hannah, R. M., Meredith, A., Aldrich, R. W., and Nelson, M. T. (2010). Astrocytic endfoot $\mathrm{Ca} 2+$ and $\mathrm{BK}$ channels determine both arteriolar dilation and constriction. Proc. Natl. Acad. Sci. U.S.A. 107, 3811-3816.

Girouard, H., and Iadecola, C. (2006). Neurovascular coupling in the normal brain and in hypertension, stroke, and Alzheimer disease. J.Appl. Physiol. 100, 328-335.

Gordon, G. R., Choi, H. B., Rungta, R. L., Ellis-Davies, G. C., and MacVicar, B. A. (2008). Brain metabolism dictates the polarity of astrocyte control over arterioles. Nature. 456, 745-749.

Gotoh, J., Kuang, T. Y., Nakao, Y., Cohen, D. M., Melzer, P., Itoh, Y., Pak, H., Pettigrew, K., and Sokoloff, L. (2001). Regional differences in mechanisms of cerebral circulatory response to neuronal activation. Am. J. Physiol. Heart Circ. Physiol. 280, H821-H829.

Hamel, E. (2006). Perivascular nerves and the regulation of cerebrovascular tone. J. Appl. Physiol. 100, 1059-1064.
Harder, D. R., Alkayed, N. J., Lange, A. R., Gebremedhin, D., and Roman, R. J. (1998). Functional hyperemia in the brain: hypothesis for astrocyte-derived vasodilator metabolites. Stroke 29, 229-234.

Heintz, N. (2001). BAC to the future: the use of bac transgenic mice for neuroscience research. Nat. Rev. Neurosci. 2, 861-870.

Hillman, E. M., Devor, A., Bouchard, M. B., Dunn, A. K., Krauss, G. W., Skoch, J., Bacskai, B. J., Dale, A. M., and Boas, D. A. (2007). Depth-resolved optical imaging and microscopy of vascular compartment dynamics during somatosensory stimulation. Neuroimage $35,89-104$.

Hoffmeyer, H. W., Enager, P., Thomsen, K. J., and Lauritzen, M. J. (2007). Nonlinear neurovascular coupling in rat sensory cortex by activation of transcallosal fibers. J. Cereb. Blood Flow Metab. 27, 575-587.

Iadecola, C. (2004). Neurovascular regulation in the normal brain and in Alzheimer's disease. Nat. Rev. Neurosci. 5, 347-360.

Jones, E. G. (1970). On the mode of entry of blood vessels into the cerebral cortex. J. Anat. 106, 507-520.

Kacem, K., Lacombe, P., Seylaz, J., and Bonvento, G. (1998). Structural organization of the perivascular astrocyte endfeet and their relationship with the endothelial glucose transporter: a confocal microscopy study. Glia 23 , 1-10.

Karagiannis, A., Gallopin, T., David, C., Battaglia, D., Geoffroy, H., Rossier J., Hillman, E. M., Staiger, J. F., and Cauli, B. (2009). Classification of NPYexpressing neocortical interneurons. $J$. Neurosci. 29, 3642-3659.

Kitaura, H., Uozumi, N., Tohmi, M. Yamazaki, M., Sakimura, K., Kudoh, M.,Shimizu, T., and Shibuki, K. (2007). Roles of nitric oxide as a vasodilator in neurovascular coupling of mouse somatosensory cortex. Neurosci. Res. 59, 160-171.

Kleinfeld, D., Mitra, P. P., Helmchen, F., and Denk, W. (1998). Fluctuations and stimulus-induced changes in blood flow observed in individual capillaries in layers 2 through 4 of rat neocortex. Proc. Natl. Acad. Sci. U.S.A. 95, 15741-15746.

Kocharyan, A., Fernandes, P., Tong, X. K., Vaucher, E., and Hamel, E. (2008). Specific subtypes of cortical GABA interneurons contribute to the neurovascular coupling response to basal forebrain stimulation. J. Cereb. Blood Flow Metab. 28, 221-231.

Kubota, Y., Hattori, R., and Yui, Y. (1994). Three distinct subpopulations of GABAergic neurons in rat frontal 
agranular cortex. Brain Res. 649, 159-173.

Lauritzen, M. (2005). Reading vascular changes in brain imaging: is dendritic calcium the key? Nat. Rev. Neurosci. 6, 77-85.

Lauritzen, M., and Gold, L. (2003). Brain function and neurophysiological correlates of signals used in functional neuroimaging. J. Neurosci. 23, 3972-3980.

Lecrux, C., Kocharyan, A., Fernandes, P., Vaucher, E., and Hamel, E. (2009). "GABA, glutamate and astroglial mediators in the cortical neurovascular coupling response to basal forebrain cholinergic input," in Brain'09, Chicago. June 29-July 3, 2009. Abstract \# 59.

Leithner, C., Royl, G., Offenhauser, N., Fuchtemeier, M., Kohl-Bareis, M., Villringer,A., Dirnagl,U., and Lindauer, U. (2010). Pharmacological uncoupling of activation induced increases in CBF and CMRO(2). J. Cereb. Blood Flow Metab. 30, 311-322.

Lindauer, U., Leithner, C., Kaasch, H., Rohrer, B., Foddis, M., Fuchtemeier, M., Offenhauser, N., Steinbrink, J., Royl, G., Kohl-Bareis, M., and Dirnagl, U. (2010). Neurovascular coupling in rat brain operates independent of hemoglobin deoxygenation. J. Cereb. Blood Flow Metab. 30, 757-768.

Lindauer, U., Megow, D., Matsuda, H., and Dirnagl, U. (1999). Nitric oxide: a modulator, but not a mediator, of neurovascular coupling in rat somatosensory cortex. Am. J. Physiol. 277, H799-H811.

Liu, X., Li, C., Falck, J. R., Roman, R. J., Harder, D. R., and Koehler, R. C. (2008). Interaction of nitric oxide, 20-HETE, and EETs during functional hyperemia in whisker barrel cortex. Am. J. Physiol. Heart Circ. Physiol. 295, H619-H631.

Logothetis, N. K., Pauls, J., Augath, M., Trinath, T., and Oeltermann, A. (2001). Neurophysiological investigation of the basis of the fMRI signal. Nature 412, 150-157.

Long, J. B., Rigamonti, D. D., Dosaka, K., Kraimer, J. M., and MartinezArizala, A. (1992). Somatostatin causes vasoconstriction, reduces blood flow and increases vascular permeability in the rat central nervous system. J. Pharmacol. Exp. Ther. 260, 1425-1432.

Lu, H., Patel, S., Luo, F., Li, S. J., Hillard, C. J., Ward, B. D., and Hyde, J. S. (2004). Spatial correlations of laminar BOLD and $\mathrm{CBV}$ responses to rat whisker stimulation with neuronal activity localized by Fos expression. Magn. Reson. Med. 52, 1060-1068.
Ma, J., Ayata, C., Huang, P. L., Fishman, M. C., and Moskowitz, M. A. (1996). Regional cerebral blood flow response to vibrissal stimulation in mice lacking type I NOS gene expression. Am. J. Physiol. 270, H1085-H1090.

Meier, S. D., Kafitz, K. W., and Rose, C. R. (2008). Developmental profile and mechanisms of GABA-induced calcium signaling in hippocampal astrocytes. Glia 56, 1127-1137.

Metea, M. R., and Newman, E. A. (2006). Glial cells dilate and constrict blood vessels: a mechanism of neurovascular coupling. J. Neurosci. 26, 2862-2870.

Monyer, H., Burnashev, N., Laurie, D. J., Sakmann, B., and Seeburg, P. H. (1994). Developmental and regional expression in the rat brain and functional properties of four NMDA receptors. Neuron 12, 529-540.

Morrison, J. H., Magistretti, P. J., Benoit, R., and Bloom, F. E. (1984). The distribution and morphological characteristics of the intracortical VIP-positive cell: an immunohistochemical analysis. Brain Res. 292, 269-282.

Mulligan, S. J., and MacVicar, B.A. (2004). Calcium transients in astrocyte endfeet cause cerebrovascular constrictions. Nature 431, 195-199.

Murayama, M., Perez-Garci, E., Nevian, T., Bock, T., Senn, W., and Larkum, M. E. (2009). Dendritic encoding of sensory stimuli controlled by deep cortical interneurons. Nature 457, 1137-1141.

Niessing, J., Ebisch, B., Schmidt, K. E., Niessing, M., Singer, W., and Galuske, R. A. (2005). Hemodynamic signals correlate tightly with synchronized gamma oscillations. Science 309, 948-951.

Nilsson, M., Eriksson, P. S., Ronnback, L., and Hansson, E. (1993). GABA induces $\mathrm{Ca} 2+$ transients in astrocytes. Neuroscience 54, 605-614.

Niwa, K., Araki, E., Morham, S. G., Ross, M. E., and Iadecola, C. (2000). Cyclooxygenase- 2 contributes to functional hyperemia in whisker-barrel cortex. J. Neurosci. 20, 763-770.

Niwa, K., Haensel, C., Ross, M. E., and Iadecola, C. (2001). Cyclooxygenase-1 participates in selected vasodilator responses of the cerebral circulation. Circ. Res. 88, 600-608.

Northington, F. J., Matherne, G. P., and Berne, R. M. (1992). Competitive inhibition of nitric oxide synthase prevents the cortical hyperemia associated with peripheral nerve stimulation. Proc. Natl. Acad. Sci. U.S.A. 89, 6649-6652.

Ohki, K., Chung, S., Ch'ng, Y. H., Kara, P., and Reid, R. C. (2005). Functional imaging with cellular resolution reveals precise micro-architecture in visual cortex. Nature 433, 597-603.

Paspalas, C. D., and Papadopoulos, G. C. (1996). Ultrastructural relationships between noradrenergic nerve fibers and non-neuronal elements in the rat cerebral cortex. Glia 17, 133-146.

Peng, X., Carhuapoma, J. R., Bhardwaj, A., Alkayed, N. J., Falck, J. R., Harder, D. R., Traystman, R. J., and Koehler, R. C. (2002). Suppression of cortical functional hyperemia to vibrissal stimulation in the rat by epoxygenase inhibitors. Am. J. Physiol. Heart Circ. Physiol. 283, H2029-H2037.

Pepicelli, O., Fedele, E., Berardi, M., Raiteri, M., Levi, G., Greco, A., jmone-Cat, M. A., and Minghetti, L. (2005). Cyclo-oxygenase- 1 and -2 differently contribute to prostaglandin E2 synthesis and lipid peroxidation after in vivo activation of $\mathrm{N}$-methyl-D-aspartate receptors in rat hippocampus. J. Neurochem. 93, 1561-1567.

Peppiatt, C. M., Howarth, C., Mobbs, P., and Attwell, D. (2006). Bidirectional control of CNS capillary diameter by pericytes. Nature 443, 700-704.

Perea, G., and Araque,A. (2005). Properties of synaptically evoked astrocyte calcium signal reveal synaptic information processing by astrocytes. $J$. Neurosci. 25, 2192-2203.

Petersen, C.C., Grinvald,A., and Sakmann, B. (2003). Spatiotemporal dynamics of sensory responses in layer $2 / 3$ of rat barrel cortex measured in vivo by voltage-sensitive dye imaging combined with whole-cell voltage recordings and neuron reconstructions. J. Neurosci. 23, 1298-1309.

Porter, J. T., and McCarthy, K. D. (1996). Hippocampal astrocytes in situ respond to glutamate released from synaptic terminals. J. Neurosci. 16, 5073-5081.

Powers, W. J., Hirsch, I. B., and Cryer, P. E. (1996). Effect of stepped hypoglycemia on regional cerebral blood flow response to physiological brain activation. Am. J. Physiol. 270, H554-H559.

Rancillac, A., Rossier, J., Guille, M., Tong, X. K., Geoffroy, H., Amatore, C., Arbault, S., Hamel, E., and Cauli, B. (2006). Glutamatergic control of microvascular tone by distinct gaba neurons in the cerebellum. J. Neurosci. 26, 6997-7006.

Rosenblum, W. I. (1986). Endothelial dependent relaxation demonstrated in vivo in cerebral arterioles. Stroke 17, 494-497.

Schleim, S., and Roiser, J. P. (2009). FMRI in translation: the challenges facing real-world applications. Front.
Hum. Neurosci. 3:63. doi: 10.3389/ neuro.09.063.2009

Schummers, J., Yu, H., and Sur, M. (2008). Tuned responses of astrocytes and their influence on hemodynamic signals in the visual cortex. Science 320 , 1638-1643.

Scremin, O. U., Rovere, A. A., Raynald, A. C., and Giardini,A. (1973). Cholinergic control of blood flow in the cerebral cortex of the rat. Stroke 4, 233-239.

Serrano, A., Haddjeri, N., Lacaille, J.C., and Robitaille, R. (2006). GABAergic network activation of glial cells underlies hippocampal heterosynaptic depression. J. Neurosci. 26, 5370-5382.

Shmuel, A., Augath, M., Oeltermann, A., and Logothetis, N. K. (2006). Negative functional MRI response correlates with decreases in neuronal activity in monkey visual area V1. Nat. Neurosci. 9, 569-577.

Shmuel, A., Yacoub, E., Pfeuffer, J., Van de Moortele, P. F., Adriany, G., Hu, X., and Ugurbil, K. (2002). Sustained negative BOLD, blood flow and oxygen consumption response and its coupling to the positive response in the human brain. Neuron 36, 1195-1210.

Sohal, V. S., Zhang, F., Yizhar, O., and Deisseroth, K. (2009). Parvalbumin neurons and gamma rhythms enhance cortical circuit performance. Nature 459, 698-702.

Somogyi, P., Hodgson, A. J., Smith, A. D., Nunzi, M. G., Gorio, A., and Wu, J. Y. (1984). Different populations of GABAergic neurons in the visual cortex and hippocampus of cat contain somatostatin- or cholecystokininimmunoreactive material. J. Neurosci. 4, 2590-2603.

Staiger, J. F., Zilles, K., and Freund, T. F. (1996). Innervation of VIPimmunoreactive neurons by the ventroposteromedial thalamic nucleus in the barrel cortex of the rat. J. Comp. Neurol. 367, 194-204.

Stark, J. A., Davies, K. E., Williams, S. R., and Luckman, S.M.(2006). Functional magnetic resonance imaging and c-Fos mapping in rats following an anorectic dose of m-chlorophenylpiperazine. Neuroimage 31, 1228-1237.

Stosiek, C., Garaschuk, O., Holthoff, K., and Konnerth, A. (2003). In vivo twophoton calcium imaging of neuronal networks. Proc. Natl. Acad. Sci. U.S.A. 100, 7319-7324.

Straub, S. V., Bonev, A. D., Wilkerson, M. K., and Nelson, M. T. (2006). Dynamic inositol trisphosphate-mediated calcium signals within astrocytic endfeet underlie vasodilation of cerebral arterioles. J. Gen. Physiol. 128, 659-669.

Straub, S. V., and Nelson, M. T. (2007). Astrocytic calcium signaling: the information currency coupling neu- 
ronal activity to the cerebral microcirculation. Trends Cardiovasc. Med. 17, 183-190.

Takano, T., Tian, G. F., Peng, W., Lou, N., Libionka, W., Han, X., and Nedergaard, M. (2006). Astrocyte-mediated control of cerebral blood flow. Nat. Neurosci. 9, 260-267.

Vaucher, E., and Hamel, E. (1995). Cholinergic basal forebrain neurons project to cortical microvessels in the rat: electron microscopic study with anterogradely transported Phaseolus vulgaris leucoagglutinin and choline acetyltransferase immunocytochemistry. J. Neurosci. 15, 7427-7441.

Vaucher,E., Tong, X. K., Cholet, N., Lantin, S., and Hamel, E. (2000). GABA neurons provide a rich input to microvessels but not nitric oxide neurons in the rat cerebral cortex: a means for direct regulation of local cerebral blood flow. J. Comp. Neurol. 421, 161-171.

Wang, H., Hitron, I. M., Iadecola, C., and Pickel, V.M. (2005). Synaptic and vascular associations of neurons containing cyclooxygenase- 2 and nitric oxide synthase in rat somatosensory cortex. Cereb. Cortex 15, 1250-1260.
Wang, J. Y., Yaksh, T. L., and Go, V. L. (1985). Studies on the in vivo release of vasoactive intestinal polypeptide (VIP) from the cerebral cortex: effects of cortical, brainstem and somatic stimuli. Brain Res. 326, 317-334.

Wang, J.Y., Yaksh, T. L., Harty, G. J., and Go, V.L. (1986). Neurotransmitter modulation of VIP release from cat cerebral cortex. Am. J. Physiol. 250, R104-R111.

Wang, X., Lou, N., Xu, Q., Tian, G. F., Peng, W. G., Han, X., Kang, J., Takano, T., and Nedergaard, M. (2006). Astrocytic $\mathrm{Ca}(2+)$ signaling evoked by sensory stimulation in vivo. Nat. Neurosci. 9 , 816-823.

Winship, I. R., Plaa, N., and Murphy, T. H. (2007). Rapid astrocyte calcium signals correlate with neuronal activity and onset of the hemodynamic response in vivo. J. Neurosci. 27, 6268-6272.

Wolf, T., Lindauer, U., Villringer, A., and Dirnagl, U. (1997). Excessive oxygen or glucose supply does not alter the blood flow response to somatosensory stimulation or spreading depression in rats. Brain Res. 761, 290-299.

Wood, J., and Garthwaite,J.(1994). Models of the diffusional spread of nitric oxide: implications for neural nitric oxide signalling and its pharmacological properties. Neuropharmacology 33 , 1235-1244.

Yaksh, T. L., Wang, J. Y., and Go, V. L. (1987). Cortical vasodilatation produced by vasoactive intestinal polypeptide (VIP) and by physiological stimuli in the cat. J. Cereb. Blood Flow Metab. 7, 315-326.

Yamada, M., Lamping, K. G., Duttaroy, A., Zhang, W., Cui, Y., Bymaster, F. P., McKinzie, D. L., Felder, C. C., Deng, C. X., Faraci, F. M., and Wess, J. (2001). Cholinergic dilation of cerebral blood vessels is abolished in M(5) muscarinic acetylcholine receptor knockout mice. Proc. Natl. Acad. Sci. U.S.A. 98, 14096-14101.

Yamagata, K., Andreasson, K. I., Kaufmann, W. E., Barnes, C. A., and Worley, P. F. (1993). Expression of a mitogen-inducible cyclooxygenase in brain neurons: regulation by synaptic activity and glucocorticoids. Neuron 11, 371-386.

Zlokovic, B.V.(2008). The blood-brain barrier in health and chronic neurodegenerative disorders. Neuron 57, 178-201.
Zonta, M., Angulo, M. C., Gobbo, S., Rosengarten, B., Hossmann, K. A., Pozzan, T., and Carmignoto, G. (2003). Neuron-to-astrocyte signaling is central to the dynamic control of brain microcirculation. Nat. Neurosci. 6, 43-50.

Conflict of Interest Statement: The authors declare that the research was conducted in the absence of any commercial or financial relationships that could be construed as a potential conflict of interest.

Received: 18 March 2010; paper pending published: 15 April 2010; accepted: 26 May 2010; published online: 23 June 2010.

Citation: Cauli B and Hamel E (2010) Revisiting the role of neurons in neurovascular coupling. Front. Neuroenerg. 2:9. doi: 10.3389/fnene.2010.00009 Copyright (C) 2010 Cauli and Hamel. This is an open-access article subject to an exclusive license agreement between the authors and the Frontiers Research Foundation, which permits unrestricted use, distribution, and reproduction in any medium, provided the original authors and source are credited. 